\title{
The targeted SMAC mimetic SW IV-134 augments platinum-based chemotherapy in pre-clinical models of ovarian cancer
}

\section{Pratibha S. Binder}

Division of Gynecologic Oncology, Department of Obstetrics and Gynecology, Washington University School of Medicine, St. Louis, MO

\section{Yassar M. Hashim}

Department of Surgery, Washington University School of Medicine, St. Louis, MO

\section{James Cripe}

Division of Gynecologic Oncology, Department of Obstetrics and Gynecology, Washington University School of Medicine, St. Louis, MO

\section{Tommy Buchanan}

Division of Gynecologic Oncology, Department of Obstetrics and Gynecology, Washington University School of Medicine, St. Louis, MO

\section{Abigail Zamorano}

Division of Gynecologic Oncology, Department of Obstetrics and Gynecology, Washington University School of Medicine, St. Louis, MO

\section{Suwanna Vangveravong}

Department of Surgery, Washington University School of Medicine, St. Louis, MO

\section{David G. Mutch}

Division of Gynecologic Oncology, Department of Obstetrics and Gynecology, Washington University School of Medicine, St. Louis, MO

\section{William G. Hawkins}

Department of Surgery, Washington University School of Medicine, St. Louis, MO

\section{Matthew A. Powell}

Division of Gynecologic Oncology, Department of Obstetrics and Gynecology, Washington University School of Medicine, St. Louis, MO

\section{Dirk Spitzer ( $\nabla$ dmpitzer@wustl.edu )}

Department of Surgery, Washington University School of Medicine, St. Louis, MO

\section{Research Article}

Keywords: Sigma-2 receptors, Sigma-2/SMAC drug conjugate, cisplatin, combination therapy, ovarian cancer 
Posted Date: January 12th, 2022

DOI: https://doi.org/10.21203/rs.3.rs-1153043/v1

License: (1) This work is licensed under a Creative Commons Attribution 4.0 International License. Read Full License

Version of Record: A version of this preprint was published at BMC Cancer on March 12th, 2022. See the published version at https://doi.org/10.1186/s12885-022-09367-w. 


\section{The targeted SMAC mimetic SW IV-134 augments platinum-based chemotherapy in pre-clinical}

Pratibha S. Binder ${ }^{1 \dagger}$, Yassar M. Hashim ${ }^{2 \dagger \dagger}$, James Cripe $^{1}$, Tommy Buchanan ${ }^{1}$, Abigail Zamorano ${ }^{1}$, Suwanna Vangveravong ${ }^{2}$, David G. Mutch ${ }^{1,3}$, William G. Hawkins ${ }^{2,3}$, Matthew A. Powell ${ }^{1,3}$ and Dirk Spitzer $^{2,3 *}$

${ }^{1}$ Division of Gynecologic Oncology, Department of Obstetrics and Gynecology, Washington University School of Medicine, St. Louis, MO

${ }^{2}$ Department of Surgery, Washington University School of Medicine, St. Louis, MO

${ }^{3}$ Alvin J. Siteman Cancer Center, St. Louis, MO, United States of America.

†Current Address:

Pratibha S Binder

Rebecca and John Moores Cancer Center

3855 Health Science Drive

La Jolla, CA

Email: pbinder@health.ucsd.edu
${ }^{\dagger}$ Current Address:

Yassar Hashim

Cedars Sinai Medical Center

8635 W. 3rd Street

Los Angeles, CA

Email: Yassar.Hashim@cshs.org

*Corresponding author:

Dirk Spitzer, PhD

Department of Surgery

Washington University School of Medicine

660 S. Euclid Ave, Box 8109

Saint Louis, MO 63110

Office: (314) 362-8631

Fax: (314) 747-2977

Email: dmpitzer@wustl.edu

29

E-mail addresses:

PSB: pbinder@ucsd.edu

YMH: Yassar.Hashim@cshs.org

JC: jcripe@ecommunity.com

TB: Txb348@jefferson.edu

AZ: a.f.smith@wustl.edu

SW: vangveravongs@wustl.edu

DGM: mutchd@wustl.edu

WGH: hawkinsw@wustl.edu

MAP: mpowell@wustl.edu

DS: dmspitzer@wustl.edu; 


\section{Abstract}

Background: Ovarian cancer is initially responsive to frontline chemotherapy. Unfortunately, it often recurs and becomes resistant to available therapies and the survival rate for advanced and recurrent ovarian cancer is unacceptably low. We thus hypothesized that it would be possible to achieve more durable treatment responses by combining cisplatin chemotherapy with SW IV-134, a cancer-targeted peptide mimetic and inducer of cell death. SW IV-134 is a recently developed small molecule conjugate linking a sigma-2 ligand with a peptide analog (mimetic) of the intrinsic death pathway activator SMAC (second-mitochondria activator of caspases). The sigma-2 receptor is overexpressed in ovarian cancer and the sigma-2 ligand portion of the conjugate facilitates cancer selectivity. The effector portion of the conjugate is expected to synergize with cisplatin chemotherapy and the cancer selectivity is expected to reduce putative off-target toxicities.

Methods: Ovarian cancer cell lines were treated with cisplatin alone, SW IV-134 alone and a combination of the two drugs. Treatment efficacy was determined using luminescent cell viability assays. Caspase-3/7, -8 and -9 activities were measured as complementary indicators of death pathway activation. Syngeneic mouse models and patient-derived xenograft (PDX) models of human ovarian cancer were studied for response to SW IV-134 and cisplatin monotherapy as well as combination therapy. Efficacy of the therapy was measured by tumor growth rate and survival as the primary readouts. Potential drug related toxicities were assessed at necropsy.

Results: The combination treatment was consistently superior in multiple cell lines when compared to the single agents in vitro. The expected mechanism of tumor cell death, such as caspase activation, was confirmed using luminescent and flow cytometry-based assay systems. Combination therapy proved to be superior in both syngeneic and PDX-based murine models of ovarian cancer. Most notably, combination therapy resulted in a complete resolution of established tumors in all study animals in a patient-derived xenograft model of ovarian cancer.

Conclusions: The addition of SW IV-134 in combination with cisplatin chemotherapy represents a promising treatment option that warrants further pre-clinical development and evaluation as a therapy for 
women with advanced ovarian cancer.

71

72 Key Words: Sigma-2 receptors, Sigma-2/SMAC drug conjugate, cisplatin, combination therapy, ovarian 73 cancer.

\section{Background}

77 The majority of patients diagnosed with ovarian, fallopian or primary peritoneal cancer, commonly 78 referred to as Mullerian cancer, present with advanced stage disease [1]. Primary treatment includes a 79 combination of cytoreductive surgery and systemic chemotherapy. Upfront surgery followed by chemotherapy or interval surgery after several cycles of chemotherapy have been employed as standard therapeutic options. Chemotherapy followed by surgery increases the likelihood of complete resection

82 with no gross residual cancer behind at the surgical sites with acceptable morbidity [2-4]. The 83 recommended first line chemotherapies include platinum- and taxane-based regimens, both via 84 intravenous (IV) and intraperitoneal (IP) administration routes [5-7]. Recently, an anti-angiogenic drug, 85 bevacizumab, was approved in combination with chemotherapy as a maintenance regimen for patients 86 with stage III or IV epithelial Mullerian cancer after initial surgical resection. This combination led to a 87 modest improvement in progression-free survival, but overall survival benefit was only seen in patients 88 with high-risk disease $[8,9]$. Also, therapies targeting the DNA replication machinery of the cells with 89 Poly (ADP-ribose) polymerase inhibitors (PARP-inh) have been approved as maintenance regimen in 90 patients with and without homologous recombination repair deficiency (HRD) and has significantly 91 improved survival in patients with HRD [10-12].

92 Most ovarian cancer patients tolerate initial chemotherapy well. However, $10 \%-58 \%$ of patients do not 93 complete the initial six-cycle regimen due to severe toxicities, including thrombocytopenia, neutropenia,

94 gastrointestinal symptoms, neuropathy and other drug-related reactions [5-7]. These toxicities may result 95 in dose delays, dose reductions, changes in chemotherapy regimen, or the addition of medications for 96 bone marrow support. The majority of patients will achieve a complete clinical response to primary 
treatment; unfortunately, $70 \%$ will recur within three years, and over $85 \%$ will recur within five years after diagnosis [13-15]. If recurrence starts more than six months after completion of primary therapy, the recommended follow-up treatment is platinum-based combination therapy. While second-line treatment is available, it is limited due to increased toxicity and decreased efficacy.

Apoptosis represents an important mechanism of cancer cell death but is often blocked during disease initiation and progression [16]. More specifically, the X-linked inhibitor of apoptosis proteins (XIAP), is a potent negative regulator of the apoptotic pathways involving caspases-3, -7 and -9 blockade and thus promotes cancer cell survival via overexpression [17-19]. As such, down-modulation of XIAP activity has been studied as a mechanism to increase apoptosis and to overcome continued cell proliferation in vitro and in preclinical mouse models of ovarian cancer [20-22]. Second mitochondria-derived activator of caspases (SMAC) is an endogenous negative regulator of inhibitors of apoptosis proteins, including XIAP and cellular IAP (cIAP) and, in doing so, restores caspase activity and cancer cell death [23]. These findings have initiated the development of synthetic small molecule mimics of endogenous SMAC protein, which have been studied in a wide variety of human malignancies, including ovarian cancer,

111 either as single agents or in combination with platinum-based therapies as a means to further improve 112 patient outcomes [24-29].

113 In an attempt to further improve the therapeutic index of cancer drugs and to minimize off-site toxicities, 114 our laboratory has developed a drug delivery concept that is based on the chemical conjugation of small 115 molecule compounds, such as the SMAC mimetic SW IV-52, to ligands, e.g. SW43 to the sigma-2 116 receptor - highly upregulated in a number of solid tumors, including ovarian cancer [30]. This conjugation 117 process resulted in a novel chemical entity, SW IV-134, that combines an improved internalization 118 efficacy into the cancer cells with superior cytotoxicity, mediated via the distinct structural domains of the 119 dual-functional drug conjugate [31]. Recently, we have shown that SW IV-134 induced much stronger 120 cytotoxicity than its individual components administered as equimolar mixes, decreased the tumor burden 121 and improved animal survival in a mouse xenograft model of ovarian cancer [32]. Since one of the 122 limitations of platinum-based chemotherapy is significant systemic toxicity and cancer cell resistance, we 
sought to demonstrate that the targeted SMAC mimetic SW IV-134 in combination with low-dose

124 cisplatin chemotherapy would provide efficient treatment benefits while systemic toxicities are reduced to

125 a minimum.

127 Methods

128 Compounds

129 The synthesis of SW IV-134 was performed in our laboratory and has been previously described [31, 32].

130 Cisplatin was purchased from the pharmacy at Washington University School of Medicine.

132 Cell lines

133 OVCAR-3 cells were purchased from American Type Culture Collection (ATCC, Manassas, VA) 134 and cultured under ATCC-recommended conditions. SKOV-3 cells obtained from Dr. Robert Mach 135 (Washington University School of Medicine, St. Louis, MO) were maintained in McCoy's 5a medium 136 containing $2 \mathrm{mM}$ Glutamine and 10\% Fetal Bovine Serum (FBS). ID8 mouse ovarian surface epithelial 137 cells (MOSEC) obtained from Dr. Kathy Roby (Kansas University Medical Center, Kansas City, KS) 138 were maintained in Dulbecco's Modified Eagle's medium (DMEM, Gibco-Life Technologies) containing $1394 \%$ FBS. ID8 cells were labeled with eYFP/luciferase reporter fusion protein by retroviral infection to 140 generate ID8-Luey cells. Protein expression was confirmed in $75 \%$ of the cells by flow cytometry and in 141 vitro luciferin conversion. Antibiotics, penicillin $(100 \mu \mathrm{g} / \mathrm{mL})$ and streptomycin $(100 \mu \mathrm{g} / \mathrm{mL})$ were added 142 to the media. Cells were maintained in a humidified incubator at $37{ }^{\circ} \mathrm{C}$ with $5 \% \mathrm{CO}_{2}$. All cell lines were 143 confirmed to be mycoplasma-negative prior to initiation of experiments.

\section{Mice}

146 C57BL/6 mice, NSG and NOD.CB17-PRKDSCID mice were obtained from Jackson Laboratory at age 6

$147-8$ weeks. Injection of tumor cells or transplant of tumor tissues was performed no sooner than one week 148 after the mice were received. All animal experimentation was performed in accordance with the 
Washington University Division of Comparative Medicine guidelines for care and use of laboratory animals. The protocol was approved by the Animal Studies Committee of Washington University 151 (protocol 20130073). End points for euthanasia included excessive lethargy, decreased motility, tumor 152 ulceration or cross-sectional tumor diameter greater than $2 \mathrm{~cm}$.

\section{Evaluation of cytotoxicity in vitro}

155 SKOV-3 cells were plated at a density of $1 \times 10^{4} /$ well, OVCAR-3 at a density of $1.5 \times 10^{4} /$ well and ID8 at 156 a density of $3 \times 10^{3} /$ well in 96-well plates for 24 hours prior to treatment. Cisplatin was dissolved in PBS 157 to achieve a concentration of $5 \mu \mathrm{g} / \mathrm{mL}$. SW IV-134 was dissolved in dimethyl sulfoxide (DMSO) and 158 diluted in culture medium to achieve a final concentration of $0.25 \mu \mathrm{M}$ for SKOV-3 cells, $4 \mu \mathrm{M}$ for 159 OVCAR-3 cells and $2 \mu \mathrm{M}$ for ID8 cells (DMSO concentration was kept below $1 \%$ to have no impact on experimental results). Cells were treated with cisplatin, SW IV-134, and a combination of the two drugs for 72 hours (SKOV-3 and OVCAR-3) and for 36 hours (ID8), respectively. Cell viability was determined using CellTiter-Glo Luminescent Viability Assay (Promega, Madison, WI). Luminescence signal was measured using a multi-mode microplate reader (Bio-Tek, Winooski, VT). All assays were 164 performed in triplicates.

\section{In vitro caspase activation assays}

167 ID8 cells were plated at a density of $3 \times 10^{3}$ in 96-well plates for 24 hours prior to treatment. The 168 following day, the cells were treated with $5 \mu \mathrm{g} / \mathrm{mL}$ cisplatin, $1 \mu \mathrm{M} \mathrm{SW}$ IV-134, a combination of the two 169 drugs, and DMSO-containing media as a control for 48 hours. The contents of the plate were mixed using 170 an orbital shaker for 30 seconds and incubated at room temperature for 90 minutes. Caspase- $3 / 7,-8$ and -9 171 activities were measured in the plates using Caspase-Glo Assay Systems (Promega, Madison, WI) 172 according to the manufacturer's instructions. This assay is based on luminogenic caspase substrates which 173 are cleaved by activated caspases resulting in generation of a luminescence signal. Luminescence signals 174 were measured using a multi-mode microplate reader (Bio-Tek, Winooski, VT). 


\section{In vivo assessment of tumor growth, survival, and toxicity in C57BL/6 mouse model}

C57BL/6 mice were injected in the right flank with $200 \mu \mathrm{L}$ single cell suspension of $1 \times 10^{7}$ ID8-Luey cells in DMEM medium. Treatment started after $\sim 4$ weeks when tumors were established to be growing and reached $6-7 \mathrm{~mm}$ in diameter. Mice were randomized into four groups with 10 mice per group $(\mathrm{n}=$ 10). Treatment included intraperitoneal injection of $100 \mu \mathrm{L}$ of vehicle daily (25\% cremophor-EL in water), SW IV-134 (500 nanomoles) daily, cisplatin ( $2 \mathrm{mg} / \mathrm{kg})$ every 3 days or combination of SW IV134 (500 nanomoles) daily and cisplatin $(2 \mathrm{mg} / \mathrm{kg})$ every 3 days for a total of 21 days. On the days mice received both SW IV-134 and cisplatin, and as a preventive measure, the injections were given at least two hours apart in case of potential drug incompatibilities regarding their respective solvent requirements. Tumors were measured every 2-3 days with a digital caliper and the volumes were calculated using the equation $\mathrm{V}=\mathrm{d}_{1} \mathrm{x}\left(\mathrm{d}_{2}\right)^{2} / 2,\left(\mathrm{~V}=\right.$ volume, $\mathrm{d}_{1}=$ larger diameter, $\mathrm{d}_{2}=$ smaller diameter $)$. Mice were euthanized using a carbon-dioxide chambers when tumors reached a diameter of $2 \mathrm{~cm}$ or became ulcerated. In order to probe for potential drug toxicities, 12 additional naive mice were treated with same treatment regimens described above ( $n=3$ /group), and sent for autopsy at the end of the 21-day treatment interval (Division of Comparative Medicine, Washington University). Blood was collected for complete blood count (CBC) and biochemical analysis (AST, ALT, BUN, total bilirubin, and Cr). Organs were examined grossly and histologically.

\section{PDX model and in vivo assessment of tumor growth and survival}

Omental metastatic tumor was harvested from a patient undergoing cytoreductive surgery for ovarian cancer and placed in RPMI on ice. The harvested tumor was divided into four $5 \mathrm{~mm}$ tumors and implanted into the right flank of two NSG mice under general anesthesia. Implantation was performed within 20 minutes of tissue harvest. Once the tumors grew larger than $15 \mathrm{~mm}$, they were harvested and implanted into subsequent NSG mice to generate stable in vivo PDX lines (three passages). Hematoxylin and eosin staining (H\&E) of an established PDX tumor was harvested and confirmed its initial characteristics determined at biopsy - high-grade serous adenocarcinoma (Suppl. Fig. S1). This confirmed 
tumor was then transplanted into the flanks of 25 NOD.CB17-PRKDSCID mice. Tumors were 202 established and treatment started at $\sim 150 \mathrm{~mm}^{3}$ tumor volume. Mice were randomized into four treatment 203 groups with five mice per group $(n=5)$. The mice then received daily intraperitoneal injections with 100 $204 \mu \mathrm{L}$ of vehicle (25\% cremophor in $\mathrm{H}_{2} \mathrm{O}$ ), weekly cisplatin $4 \mathrm{mg} / \mathrm{kg}$, daily SW IV-134 (750 nmoles), and a 205 combination of daily SW IV-134 (750 nmoles) and weekly cisplatin $4 \mathrm{mg} / \mathrm{kg}$ for 14 days. Tumors were 206 measured every 3 - 4 days with a digital caliper and mice were euthanized when tumors reached a cross207 sectional diameter of $2 \mathrm{~cm}$ or ulcerated.

\section{Statistics}

210 Statistical analyses and data plotting were performed using GraphPad Prism software version 8 (San 211 Diego, CA) and IBM SPSS Statistics 25 (Armonk, NY). Results were expressed as mean \pm SEM of at 212 least 3 biological replicates for in vitro data. One-way ANOVA was used to analyze the differences in 213 viability and caspase activity assays. Unpaired two tailed t-tests were used to evaluate the difference in $214 \mathrm{CBC}$, biochemistry analyses, and to confirm the difference in subgroups. Mixed model two-way ANOVA 215 was used to analyze the difference in tumor sizes in order to adjust for missing data when mice died or 216 were euthanized. Kaplan-Meier survival analysis was used and the difference between the groups was 217 compared with a log-rank test. A $p$-value of $<0.05$ was considered significant for all analyses. 


\section{Results}

The targeted SMAC mimetic SW IV-134 is a potent enhancer of cisplatin-induced cell death

229 Three frequently utilized ovarian cancer cell lines were chosen for our initial treatment assessments. In 230 order to investigate the combined effects of our study drugs, we determined the minimally effective dose 231 of each drug alone in a series of pilot experiments. The drug concentration required to induce limited cell death $(50 \%$ or less) varied between cell lines and ranged from $0.25 \mu \mathrm{M}$ (SKOV-3, human) to $4 \mu \mathrm{M}$ (OVCAR3, human), with ID8 cells (mouse) requiring an intermediate dose of $2 \mu \mathrm{M}$ (Fig. 1, blue and red bars). To test whether a combination of these sublethal doses would increase cell death beyond singleagent potency, we treated SKOV-3, OVCAR3 and ID8 cells with a combination of both compounds. Indeed, the drug combinations substantially increased the overall cytotoxicity in all cell lines with OVCAR3 cells (20\% viability), being less sensitive than SKOV-3 and ID8 cells (5\% viability) (Fig. 1A $\mathrm{C}, p<0.001$ for all analyses). The response to combination treatment was far more pronounced than anticipated, given the modest cytotoxicity of the individual components suggesting a synergistic rather than an additive mode of action.

A.

SKOV-3 cells

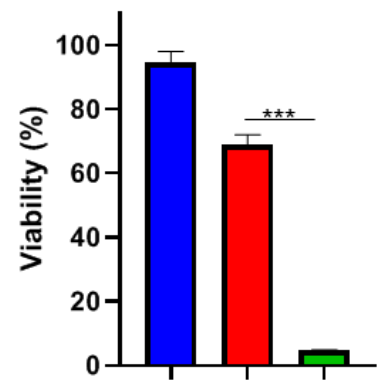

241

242

243

244
B.

OVCAR 3 cells
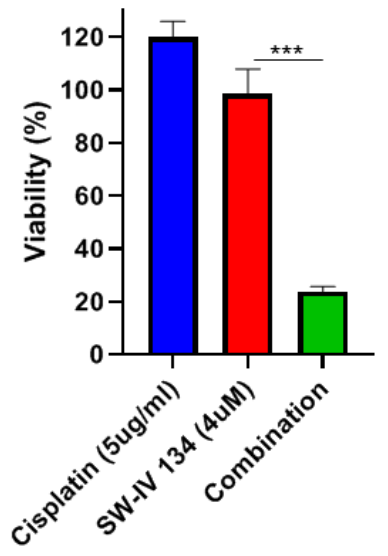

C. ID8 cells

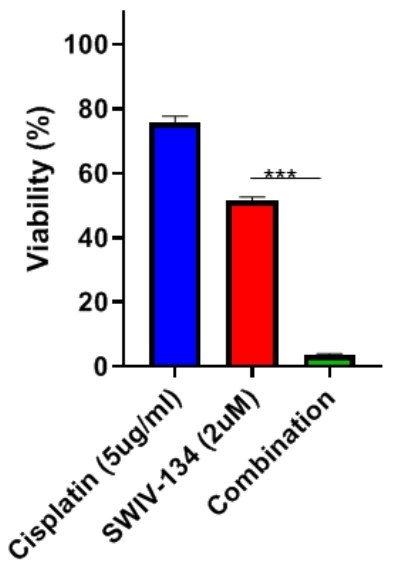

Figure 1. The combination of cisplatin and SW IV-134 shows enhanced reduction in ovarian cancer cell viability. A, SKOV-3, B, OVCAR-3 and C, ID8 cells were treated with cisplatin (5ug/ml), SW IV134 (varying concentrations), or the combination of the two drugs using the same concentrations. Titer- 
Glo viability assays were performed after 72 hours (SKOV-3 and OVCAR-3) or 36 hours (ID8) of treatment. The data were normalized to DMSO treated control cells. $(* * * p<0.001)(n=3)$.

Since SW IV-134 is designed to interfere with XIAP, in effect increasing the activity of intracellular caspases, we studied the relative contribution of drug treatment on the various effector arms of the apoptotic machinery, i.e. the activation of caspases-3/7 (terminal pathway), caspase-8 (extrinsic pathway) and caspase-9 (intrinsic pathway). Using a fluorescence-based caspase activation assay, treatment of ID8 cells with cisplatin and SW IV-134 alone induced only a slight activation process for all caspases ranging from 1.2 - 2.8-fold over baseline (Fig. 2). Combination of cisplatin and SW IV-134 led to an even further increase in caspase activity (2.5 - 5.4-fold) and reached the highest levels of activation across all singleagent regimens with one exception - caspase-9/cisplatin (Fig. 2). These data suggest that the strongest impact on overall cell death induction is likely mediated via the terminal apoptosis pathway (executioner caspase-3).

ID8 cells

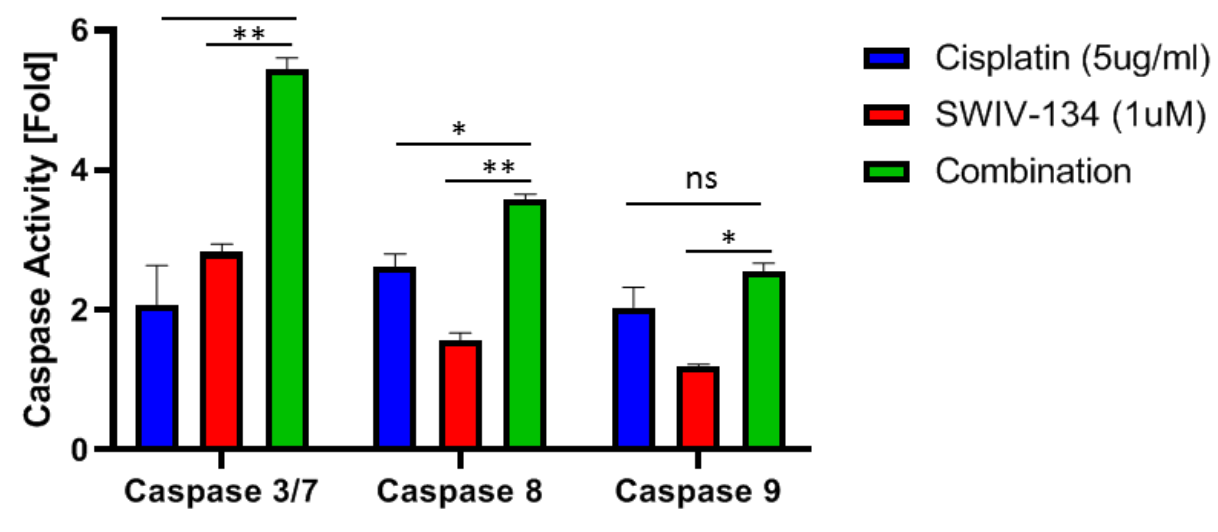

Figure 2. The combination of cisplatin and SW IV-134 leads to augmented apoptotic cell death.

Mouse ID8 cells were treated with cisplatin $(5 \mu \mathrm{g} / \mathrm{mL})$, SW IV-134 $(1 \mu \mathrm{M})$, and a combination of the two drugs at their respective concentrations. The activation status of caspases 3,8 and 9 were measured using cells treated with DMSO (baseline) $(\mathrm{n}=3, * \mathrm{p}<0.001, * * \mathrm{p}<0.0001, \mathrm{~ns}=$ non-significant). 

immunocompetent mouse model of ovarian cancer (syngeneic model) In order to determine if the drug combination concept observed in vitro would translate to a similar response in vivo, we applied a syngeneic animal model by injecting luciferase-labeled ID8 ovarian cancer cells (ID8-Luey) into the flanks of immunocompetent C57BL/6 mice. The mice were randomized into four groups and a three-week treatment regimen started when tumor volumes reached $\sim 100 \mathrm{~mm}^{3}$. Mice treated with vehicle served as a control. Both single-agent treatment arms showed little signs of treatment response, reflected by tumor growth patterns similar to the vehicle control. In contrast, the combination group demonstrated a strong treatment response, associated with tumor shrinkage, which started shortly after drug administration (Fig. 3A). About 14 days into the treatment period, both single-agent groups appeared to develop mild treatment responses and a reduction in tumor size. Several days post-treatment cessation, the tumors of all groups started growing again, albeit at differential kinetics, with the control and single-agent groups resuming at a higher growth pace than the combination group (Fig. 3A, $p<$ 0.0001). The median survival of the combination group was nearly twice as along (76 days) as the most effective monotherapy (cisplatin, 46 days), followed by vehicle (36 days) and SW IV-134 (34 days), respectively (Fig. 3B, $p<0.0001$ ). Of note, two out of ten mice $(20 \%)$ in the combination group survived for more than 100 days, while no such long-term survivors were identified in any other treatment group. We did not observe significant differences in complete blood counts or serum chemistry between the treatment groups, indicative of only mild, if any systemic toxicities of drug therapies (Suppl. Table S1). Some mice demonstrated mild irritation or ulcers at the site of peritoneal drug injection as well as slight initial weight loss (SW IV-134). However, this trend did not continue and all mice recovered from this drug effect by day 10 of therapy. In addition, organ analysis (brain, heart, lungs, alimentary tract, kidneys, liver and pancreas) did not reveal signs of adverse drug effects and the absence of discernible change in mouse behavior (failure to groom) and treatment-related deaths further support the notion that SW IV134/cisplatin combination therapy was well tolerated. 


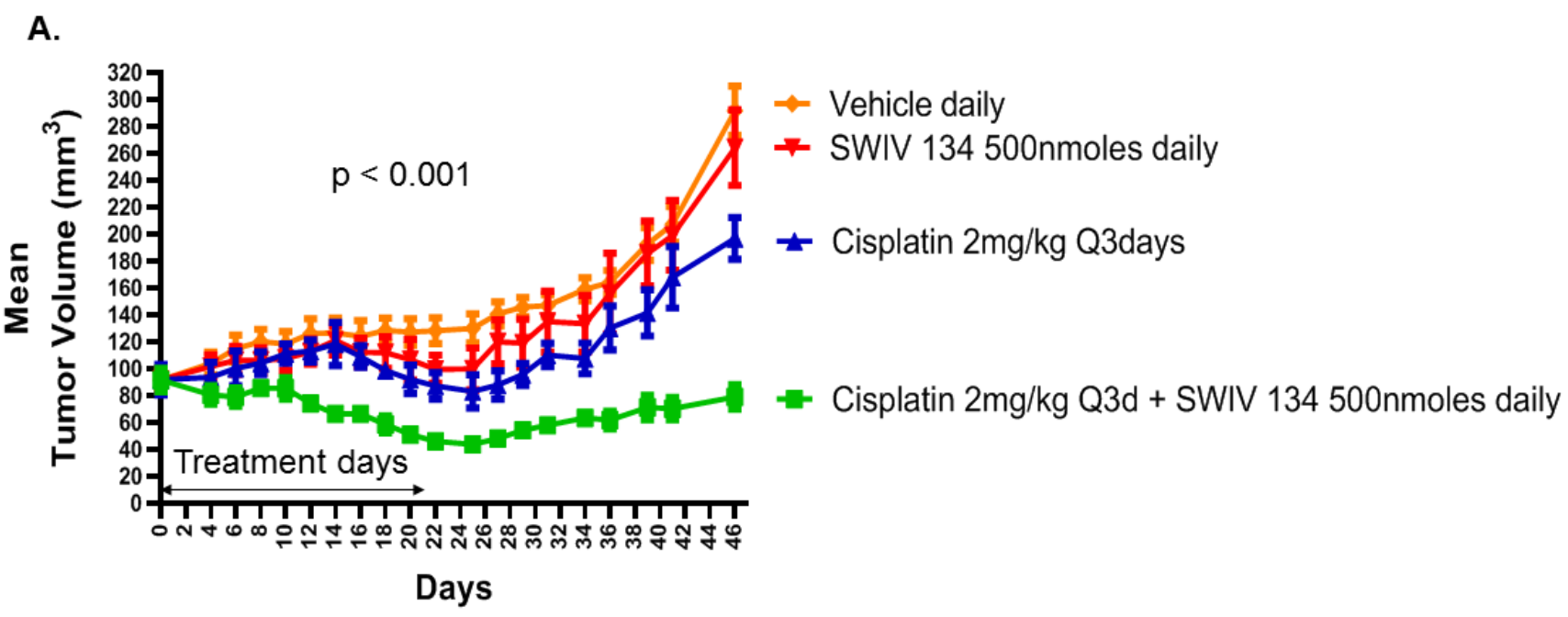

B.

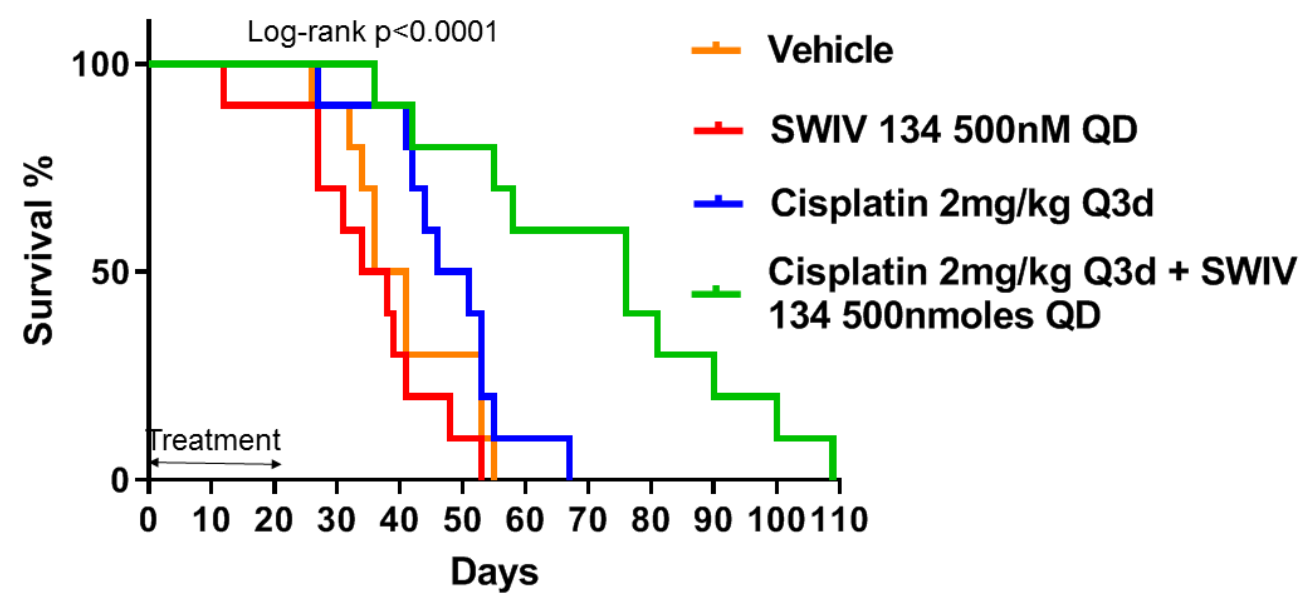

293 Figure 3. The combination of SW IV-134 and Cisplatin therapy leads to improved objective

294 response rate and survival in an immune-competent ovarian cancer mouse model. An immune-

295 competent allograft mouse model of ovarian cancer was established after right flank injection a $200 \mu \mathrm{L}$

296 single cell suspension of $1 \times 10^{7}$ ID8-Luey cells. The mice were treated with the above 4 treatment

297 regimen with vehicle being the control group. A, The tumors were measured every other day using digital 298 calipers. The change in tumor volumes between the groups was statistically significant with the tumor 299 volumes of the combination group being significantly lower than vehicle $(p<0.0001)$, SWIV $-134(p=$ 300 0.01) and cisplatin ( $\mathrm{p}=0.001)$ at 36 days. B, Kaplan-Meier survival curve of mice in (A). Survival of the 301 combination treatment group was significantly longer than any other treatment group with median 
survival being 36, 34, 46 and 76 days in the vehicle, SW IV-134 alone, cisplatin alone and combination treatment groups, respectively $(\mathrm{p}<0.001)$.

SW IV-134/cisplatin combination therapy leads to complete tumor eradication in a patient-derived xenograft (PDX) model of ovarian cancer

With the goal of performing a clinically more relevant efficacy model, we successfully generated a patient-derived tumor line in immunocompromised mice using omental tumor tissue obtained from a woman with a fallopian tube carcinoma undergoing cytoreductive surgery. In order for it to be considered a stable PDX line, the initial tumor implant was passaged four times using naïve founder mice. At this point, the tumor was harvested and H\&E staining confirmed a high-grade serous carcinoma (Suppl. Fig. S1). Tumor tissues $(5 \mathrm{~mm})$ were transplanted into NOD.CB17-PRKDSCID experimental mice. When the tumor volumes reached $\sim 150 \mathrm{~mm}^{3}$, the mice were randomized and treated using the same conditions and shorter schedule than described above for the syngeneic mouse model. complete disappearance of visible tumors in three of the mice $(60 \%)$ without signs of disease recurrence throughout their lifetime (Fig. 4A, $p<0.0001$ ). Similar to the syngeneic tumor model described above, we noticed some response to the single-agent groups after $\sim 15$ days of treatment. Shortly after treatment cessation, tumors started growing again with cisplatin alone being somewhat more effective than SW IV134 alone, illustrated by a more rapid tumor growth curve in the latter group. Three of the mice in the combination group died of natural causes while the median survival of mice treated with vehicle, SW IV-

323134 alone and cisplatin alone was 56, 70 and 102 days, respectively (Fig. 4B, $p<0.0001$ ). We observed 324 some weight loss in the mice treated with Cisplatin but failed to detect abnormalities in mouse behavior 325 (failure to groom) and drug-related deaths throughout the course of the experiment. 
A.

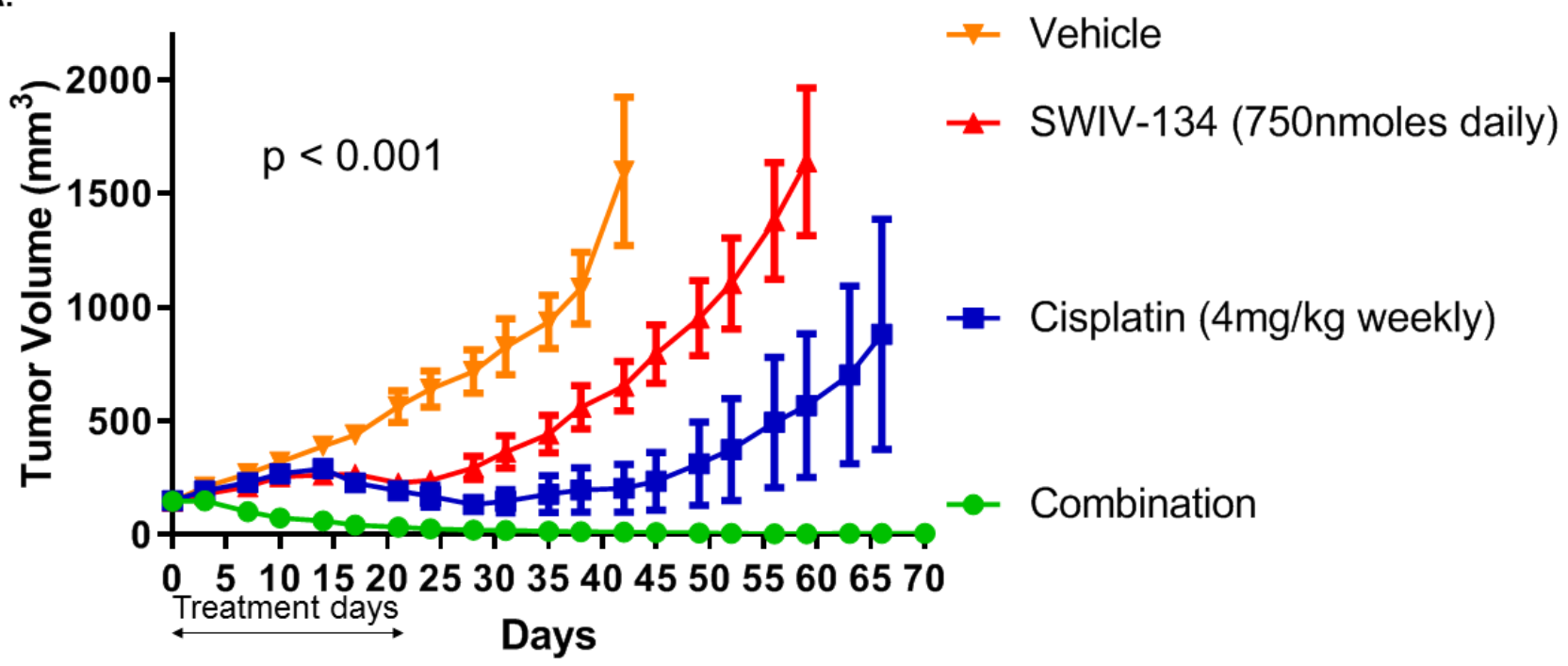

B.

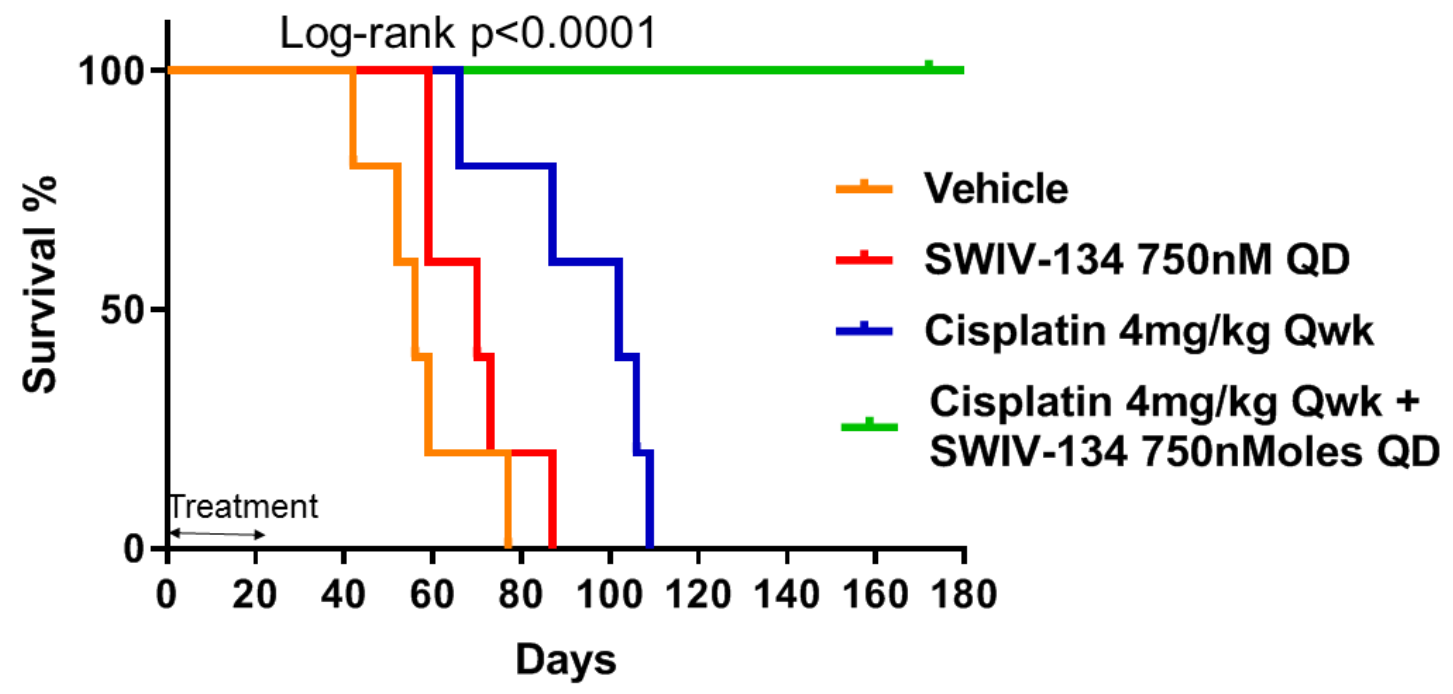

Figure 4. The combination of SW IV-134 and Cisplatin therapy leads to improved complete tumor response rate and survival in a patient-derived xenograft (PDX) model of ovarian cancer. A patientderived xenograft model of ovarian cancer was established by transplanting 5 x $5 \mathrm{~mm}$ tumors into the right flank of immunocompromised NOD.CB17-PRKDSCID female mice. Once growing tumors were confirmed, the mice were treated with the above 4 treatment regimen with vehicle being the control group. A, The tumors were measured every other day using digital calipers. The change in tumor volumes between the groups was statistically significant and only the combination therapy group saw a significant reduction in tumor volume as well as 3 complete responses. B, Kaplan-Meier survival curve of mice in 
(A). Three mice in the combination therapy group had a complete response and long-term survival until natural cause of death. The median survivals were 56, 70, 102 and 200 days in the vehicle, SW IV-134 alone, cisplatin alone and combination treatment groups, respectively $(\mathrm{p}<0.001)$.

\section{Discussion}

344 In our current study, we have evaluated a novel drug treatment and combination strategy for ovarian 345 cancer. We sought to investigate if cisplatin, an established standard-of-care treatment for Mullerian carcinomas, could be safely and effectively combined with a cancer-targeted SMAC mimetic (SW IV134) as a means to substantially improve cancer outcomes and toxicities. When used in combination, sublethal doses of cisplatin and SW IV-134 led to substantially increased death pathway activation in vitro, much more so than the individual cancer drugs were able to accomplish in isolation, suggestive of a and patient-derived xenograft (PDX) models of ovarian cancer (immunocompromised hosts), therapy led to complete responses in the PDX ovarian cancer model, in which $60 \%$ of the mice were tumor-free and showed no evidence of recurrent disease over the course of their natural lifetime. These pre-clinical studies demonstrate that the combination of cisplatin and SW IV-134 represents a viable and promising treatment strategy for Mullerian carcinomas, which include ovarian, fallopian and primary peritoneal carcinomas.

Platinum-based medications have been safely combined with other chemotherapeutics in the primary treatment of Mullerian carcinomas [5, 33-35]. In cases where the cancers recurs less than 6 months from completion of chemotherapy, platinum-based chemotherapy is usually discontinued, unless evidence of 363 resistance reversal is presented [36]. Since subsequent treatment regimens are usually associated with 
minimal efficacy and increased toxicities, we are in dire need of innovative and novel treatment strategies for recurrent Mullerian carcinomas [33-35]. Our research has demonstrated that low-dose SW IV134/cisplatin combination therapy resulted in better treatment outcomes than merely the sum of its

367 individual components, indicative of a synergistic drug interaction in the absence of overt toxicities.

368 With respect to ovarian cancer in particular, overexpression of inhibitor of apoptosis proteins (IAPs) 369 contribute to a significant degree of drug resistance by preventing efficient activation of apoptotic cell 370 death [17-19, 37]. XIAP and cIAP are the most prominent and potent members of this family and its 371 pharmacologic blockade with SMAC mimetics has been shown to sensitize ovarian cancer efficiently to 372 chemotherapy [25-29, 38]. We have previously shown that the conjugate SW IV-134 leads to rapid cell 373 death via activation of caspases, degradation of cIAP-1, cIAP-2, activation of NF-қ $\beta$ and induction of $374 \mathrm{TNF} \alpha[32,39]$. As a result, our prior research has indicated that this drug conjugate exerted increased 375 activity against ovarian cancer in vitro and in vivo, and sensitized chemo-resistant pancreatic cancer to 376 gemcitabine-based combination therapy [30-32, 39, 40]. Our next steps would be to study the role of SW

377 IV-134 in sensitizing chemotherapy resistant ovarian cancer to platinum-based chemotherapy, since 378 resistance to platinum-based chemotherapy is one of the most important prognostic factors for this 379 disease.

381 Therefore, restoring the ability to undergo programmed cell death by inhibiting XIAP and activating 382 TNF $\alpha$ via cIAP degradation appears to be an attractive strategy for the treatment of Mullerian carcinomas. 383 In order to most effectively target ovarian cancer cells and decrease systemic toxicities, the delivery of the 384 XIAP antagonist has been rendered cancer selective by linking the SMAC mimetic to the sigma-2 ligand 385 SW43, the receptors of which are upregulated in ovarian cancer cells [30]. This treatment concept uses 386 targeted therapeutics capable of delivering the cytotoxic agents directly into the cancer cells [31] and 387 requires less drug to accomplish the same biologic effects the non-targeted compounds can only achieve 388 at a much higher dose. Here, we have also shown that this novel drug can be safely used in combination 
389 with standard of care platinum-based chemotherapy with a trend toward synergistic tumor eradication and $390 \quad$ limited overall systemic toxicities.

392 Conclusions

393 Future studies are highly warranted to test our particular drug combination to obtain evidence for 394 overcoming apoptosis-related platinum resistance in Mullerian carcinomas using additional chemotherapy 395 resistant ovarian cancer but also fallopian or primary peritoneal cancer cell lines as well as patient-derived 396 tumors. Platinum-resistant and refractory ovarian cancer has a very poor prognosis with an overall 397 survival of months, and novel therapeutic approaches in this arena are thus desperately needed. Given that 398 combination therapy significantly decreased the tumor burden in immunocompetent as well as in the 399 clinically relevant patient-derived xenograft models of ovarian cancer, resulting in complete treatment 400 responses, we propose that this drug combination should be tested more broadly in PDX-based animal 401 models before advancing toward clinical trials. 
405 Ethics approval and consent to participate

406 All methods were carried out in accordance to the ethics standards of Washington University and are reported in

407 accordance with ARRIVE guidelines (https://arriveguidelines.org). Procedures involving mice were approved by

408 the Washington University Animal Studies Committee and conducted in accordance with the guidelines for the care

409 and use of laboratory research animals established by the NIH.

411 Consent for publication

412 Not applicable.

$414 \quad$ Availability of Data and Materials

415 All data generated or analyzed during this study are included in this published article [and its

416 supplementary information files].

418 Competing interests

419 The authors declare no competing interest.

\section{$421 \quad$ Funding}

422 This work was funded in part by grants from the Department of Defense (DoD) W81XWH-17-1-0102

423 (D. Spitzer) and NIH R01 CA163764 (D. Spitzer and W. Hawkins).

424

425 Author's Contributions and Acknowledgements

426 We would like to thank Deborah Frank, scientific editor, for her help proofreading our mansucript.

428 Pratibha S. Binder: PDX generation, Performed research, data analysis, manuscript writing and editing.

429 Yassar M. Hashim: Assay development, manuscript editing.

James Cripe: PDX generation, manuscript editing. 
430 Tommy Buchanan: Help with animal work, manuscript editing.

431 Abigail Zamorano: Mycoplasma testing and removal, manuscript editing.

432 Suwanna Vangveravong: Drug synthesis, manuscript editing.

433 David G. Mutch: Supervision, manuscript editing.

434 William G. Hawkins: Study advisor, manuscript editing.

435 Matthew A. Powell: Study design, supervision, manuscript editing.

436 Dirk Spitzer: Study design, supervision, manuscript editing.

437 


\section{References}

439 1. Siegel RL, Miller KD, Jemal A: Cancer statistics, 2020. CA Cancer J Clin 2020, 70(1):7-30.

440 2. Vergote I, Trope CG, Amant F, Kristensen GB, Ehlen T, Johnson N, Verheijen RH, van der Burg

441 ME, Lacave AJ, Panici PB et al: Neoadjuvant chemotherapy or primary surgery in stage

3. Kehoe S, Hook J, Nankivell M, Jayson GC, Kitchener H, Lopes T, Luesley D, Perren T, Bannoo

4. Fagotti A, Ferrandina G, Vizzielli G, Fanfani F, Gallotta V, Chiantera V, Costantini B, Margariti PA, Gueli Alletti S, Cosentino F et al: Phase III randomised clinical trial comparing primary surgery versus neoadjuvant chemotherapy in advanced epithelial ovarian cancer with high tumour load (SCORPION trial): Final analysis of peri-operative outcome. Eur J Cancer

452 5. Ozols RF, Bundy BN, Greer BE, Fowler JM, Clarke-Pearson D, Burger RA, Mannel RS, DeGeest K, Hartenbach EM, Baergen R et al: Phase III trial of carboplatin and paclitaxel compared with cisplatin and paclitaxel in patients with optimally resected stage III ovarian cancer: a Gynecologic Oncology Group study. J Clin Oncol 2003, 21(17):3194-3200.

6. Armstrong DK, Bundy B, Wenzel L, Huang HQ, Baergen R, Lele S, Copeland LJ, Walker JL, Burger RA, Gynecologic Oncology G: Intraperitoneal cisplatin and paclitaxel in ovarian cancer. $N$ Engl J Med 2006, 354(1):34-43. 
8. Burger RA, Brady MF, Bookman MA, Fleming GF, Monk BJ, Huang H, Mannel RS, Homesley $\mathrm{HD}$, Fowler J, Greer BE et al: Incorporation of bevacizumab in the primary treatment of ovarian cancer. $N$ Engl J Med 2011, 365(26):2473-2483.

9. Tewari KS, Burger RA, Enserro D, Norquist BM, Swisher EM, Brady MF, Bookman MA, Fleming GF, Huang H, Homesley HD et al: Final Overall Survival of a Randomized Trial of Bevacizumab for Primary Treatment of Ovarian Cancer. J Clin Oncol 2019, 37(26):23172328.

10. Friedlander M, Moore KN, Colombo N, Scambia G, Kim BG, Oaknin A, Lisyanskaya A, Sonke GS, Gourley C, Banerjee S et al: Patient-centred outcomes and effect of disease progression on health status in patients with newly diagnosed advanced ovarian cancer and a BRCA mutation receiving maintenance olaparib or placebo (SOLO1): a randomised, phase 3 trial. Lancet Oncol 2021, 22(5):632-642.

11. DiSilvestro P, Colombo N, Scambia G, Kim BG, Oaknin A, Friedlander M, Lisyanskaya A, Floquet A, Leary A, Sonke GS et al: Efficacy of Maintenance Olaparib for Patients With Newly Diagnosed Advanced Ovarian Cancer With a BRCA Mutation: Subgroup Analysis Findings From the SOLO1 Trial. J Clin Oncol 2020, 38(30):3528-3537.

12. Ray-Coquard I, Pautier P, Pignata S, Perol D, Gonzalez-Martin A, Berger R, Fujiwara K, Vergote I, Colombo N, Maenpaa J et al: Olaparib plus Bevacizumab as First-Line Maintenance in Ovarian Cancer. N Engl J Med 2019, 381(25):2416-2428.

13. Ledermann JA, Raja FA, Fotopoulou C, Gonzalez-Martin A, Colombo N, Sessa C, Group EGW: Newly diagnosed and relapsed epithelial ovarian carcinoma: ESMO Clinical Practice Guidelines for diagnosis, treatment and follow-up. Ann Oncol 2013, 24 Suppl 6:vi24-32.

14. Gadducci A, Cosio S, Zizioli V, Notaro S, Tana R, Panattoni A, Sartori E: Patterns of Recurrence and Clinical Outcome of Patients With Stage IIIC to Stage IV Epithelial Ovarian Cancer in Complete Response After Primary Debulking Surgery Plus 
Chemotherapy or Neoadjuvant Chemotherapy Followed by Interval Debulking Surgery: An Italian Multicenter Retrospective Study. Int J Gynecol Cancer 2017, 27(1):28-36.

15. Pokhriyal R, Hariprasad R, Kumar L, Hariprasad G: Chemotherapy Resistance in Advanced

16. Armstrong DK: Relapsed ovarian cancer: challenges and management strategies for a

17. Mansouri A, Zhang Q, Ridgway LD, Tian L, Claret FX: Cisplatin resistance in an ovarian 495

18. Yang X, Xing H, Gao Q, Chen G, Lu Y, Wang S, Ma D: Regulation of HtrA2/Omi by X-linked

19. Sasaki H, Sheng Y, Kotsuji F, Tsang BK: Down-regulation of X-linked inhibitor of apoptosis

20. Ma JJ, Chen BL, Xin XY: XIAP gene downregulation by small interfering RNA inhibits

carcinoma is associated with a defect in programmed cell death control through XIAP regulation. Oncol Res 2003, 13(6-10):399-404. inhibitor of apoptosis protein in chemoresistance in human ovarian cancer cells. Gynecologic oncology 2005, 97(2):413-421.

protein induces apoptosis in chemoresistant human ovarian cancer cells. Cancer Res 2000, 60(20):5659-5666. proliferation, induces apoptosis, and reverses the cisplatin resistance of ovarian carcinoma. Eur J Obstet Gynecol Reprod Biol 2009, 146(2):222-226.

21. Chen X, Gong L, Ou R, Zheng Z, Chen J, Xie F, Huang X, Qiu J, Zhang W, Jiang Q et al: Sequential combination therapy of ovarian cancer with cisplatin and gamma-secretase inhibitor MK-0752. Gynecologic oncology 2016, 140(3):537-544.

22. Shen W, Liang B, Yin J, Li X, Cheng J: Noscapine Increases the Sensitivity of Drug-Resistant Ovarian Cancer Cell Line SKOV3/DDP to Cisplatin by Regulating Cell Cycle and Activating Apoptotic Pathways. Cell Biochem Biophys 2015, 72(1):203-213.

Du C, Fang M, Li Y, Li L, Wang X: Smac, a mitochondrial protein that promotes cytochrome c-dependent caspase activation by eliminating IAP inhibition. Cell 2000, 102(1):33-42. 
514 24. Beug ST, LaCasse EC, Korneluk RG: Smac mimetics combined with innate immune stimuli

515 create the perfect cytokine storm to kill tumor cells. Oncoimmunology 2014, 3:e28541.

516 25. La V, Fujikawa R, Janzen DM, Nunez M, Bainvoll L, Hwang L, Faull K, Lawson G,

517 Memarzadeh S: Birinapant sensitizes platinum-resistant carcinomas with high levels of cIAP 518 to carboplatin therapy. NPJ Precis Oncol 2017, 1.

519 26. Janzen DM, Tiourin E, Salehi JA, Paik DY, Lu J, Pellegrini M, Memarzadeh S: An apoptosis520 enhancing drug overcomes platinum resistance in a tumour-initiating subpopulation of $521 \quad$ ovarian cancer. Nature communications 2015, 6:7956.

522 27. Liu Y, Tong L, Luo Y, Li X, Chen G, Wang Y: Resveratrol inhibits the proliferation and 523

28. Brunckhorst MK, Lerner D, Wang S, Yu Q: AT-406, an orally active antagonist of multiple 526 inhibitor of apoptosis proteins, inhibits progression of human ovarian cancer. Cancer biology \& therapy 2012, 13(9):804-811.

528 29. Thibault B, Genre L, Le Naour A, Broca C, Mery E, Vuagniaux G, Delord JP, Wiedemann N, 529 Couderc B: DEBIO 1143, an IAP inhibitor, reverses carboplatin resistance in ovarian cancer cells and triggers apoptotic or necroptotic cell death. Sci Rep 2018, 8(1):17862.

531 30. Mach $\mathrm{RH}$, Zeng $\mathrm{C}$, Hawkins WG: The sigma2 receptor: a novel protein for the imaging and treatment of cancer. JMedChem 2013, 56(18):7137-7160.

533 31. Zeng C, Vangveravong S, McDunn JE, Hawkins WG, Mach RH: Sigma-2 receptor ligand as a

32. Garg G, Vangveravong S, Zeng C, Collins L, Hornick M, Hashim Y, Piwnica-Worms D, Powell novel method for delivering a SMAC mimetic drug for treating ovarian cancer. BrJCancer 2013, 109(9):2368-2377. MA, Mutch DG, Mach RH et al: Conjugation to a SMAC mimetic potentiates sigma-2 ligand induced tumor cell death in ovarian cancer. Molecular cancer 2014, 13:50. 
33. Pujade-Lauraine E, Wagner U, Aavall-Lundqvist E, Gebski V, Heywood M, Vasey PA, Volgger B, Vergote I, Pignata S, Ferrero A et al: Pegylated liposomal Doxorubicin and Carboplatin

34. Pfisterer J, Shannon CM, Baumann K, Rau J, Harter P, Joly F, Sehouli J, Canzler U, Schmalfeldt

35. Mullen MM, Kuroki LM, Thaker PH: Novel treatment options in platinum-sensitive recurrent

36. McMullen M, Karakasis K, Madariaga A, Oza AM: Overcoming Platinum and PARPInhibitor Resistance in Ovarian Cancer. Cancers (Basel) 2020, 12(6).

550 37. Binju M, Amaya-Padilla MA, Wan G, Gunosewoyo H, Suryo Rahmanto Y, Yu Y: Therapeutic Inducers of Apoptosis in Ovarian Cancer. Cancers (Basel) 2019, 11(11).

552 38. Rathore R, McCallum JE, Varghese E, Florea AM, Busselberg D: Overcoming chemotherapy

39. Hashim YM, Spitzer D, Vangveravong S, Hornick MC, Garg G, Hornick JR, Goedegebuure P, Mach RH, Hawkins WG: Targeted pancreatic cancer therapy with the small molecule drug conjugate SW IV-134. Molecular oncology 2014.

40. Hashim YM, Vangveravong S, Sankpal NV, Binder PS, Liu J, Goedegebuure SP, Mach RH, Spitzer D, Hawkins WG: The Targeted SMAC Mimetic SW IV-134 is a strong enhancer of standard chemotherapy in pancreatic cancer. Journal of experimental \& clinical cancer research : CR 2017, 36(1):14. 


\section{Supplementary Files}

This is a list of supplementary files associated with this preprint. Click to download.

- RawdatatoFig1Cellviabilityinvitro.xlsx

- RawdatatoFig2caspaseactivationinvitro.xIsx

- RawdatatoFig3tumorvolumesurvival.xlsx

- RawdatatoFig4tumorvolumesurvival.xlsx

- SupplementaryFigS1 andTableS1.pdf 